\title{
Do Reflexive Software Development Teams Perform Better?
}

\author{
Adarsh Kumar Kakar
}

Received: 12 May 2016/Accepted: 11 August 2016/Published online: 14 June 2017

(C) Springer Fachmedien Wiesbaden 2017

\begin{abstract}
Reflexivity, the extent to which teams reflect upon and modify their functioning, is widely recognized as a key factor influencing performance of work teams. The paper proposes that outcome interdependence, defined as the extent to which team members perceive that attainment of goals by their colleagues will facilitate their own goal achievement, will moderate the effect of team reflexivity on its performance. An empirical study with 332 team members of 34 software projects reveals that as predicted team reflexivity and outcome interdependence have both synergistic and antagonistic impacts on team performance. While high outcome interdependence magnified the positive impacts of team reflexivity on its effectiveness, an increase in team reflexivity at low outcome interdependence had a deleterious impact. However, an opposite effect was observed for team efficiency. Further, agile teams demonstrated higher outcome interdependence and team reflexivity, and thereby higher effectiveness, but lower efficiency, compared to teams adopting plan-drive methods of software development. Finally, in general, agile software development projects performed better than plan driven projects for innovative software development, while projects adopting plan-driven methods performed better than agile projects for routine software development.
\end{abstract}

Accepted after one revision by Prof. Dr. Becker.

Electronic supplementary material The online version of this article (doi:10.1007/s12599-017-0481-5) contains supplementary material, which is available to authorized users.

Prof. A. K. Kakar $(\bowtie)$

Alabama State University, 113, InTown Suites, 3670 Richard

Road, Montgomery, AL 36111, USA

e-mail: akakar@alasu.edu
Keywords Agile Software development · Plan-driven development . Team performance

\section{Introduction}

Although there is a large body of work investigating the effects of team characteristics on its performance, most team studies assume that teams operate in a static environment. However, in the modern workplace, organizations and teams face greater uncertainty and complexity than they have ever in the past (Parker et al. 2001). Many of these factors are external to the organization and therefore difficult to control such as uncertain customer requirements or demands, and the ever-increasing rate of changing technologies, economic conditions and competition. These uncertainties result in unpredictability in the inputs, processes, or outputs of work systems (Wall et al. 2002; Wright and Cordery 1999).

Keeping in view that most organizations deploy teams to accomplish work (Osterman 2000), including developing software, it is important for teams to function in a way that enables them to cope successfully in an environment of uncertainty and change. This is especially relevant for nonroutine jobs such as software development which requires a myriad of complex problems to be solved using a variety of skill and personalities (Capretz 2003). In an environment of ever changing customer requirements and technological changes there is a need for continuous reflection to decide on the best course of action.

A key mechanism that enables teams to monitor and react successfully to their environment is reflexivity (West 2000). Team reflexivity is defined as the "extent to which group members overtly reflect upon the group's objectives, strategies and processes, and adapt them to current or 
anticipated endogenous or environmental circumstances" (West 1996). It involves constant questioning, explorations and analysis. Reflexivity is critical for recognizing changes in external as well as internal environment and for learning. It is therefore not surprising that reflexivity is positively linked to team performance and creativity (De Dreu 2002).

A reflexive team is said to be more aware of the consequences of its actions and thereby its ability to adapt under rapidly evolving situations. But does an increase in team reflexivity always enhance team performance? Gleaning concepts from a multi-disciplinary research on work design in teams we propose that teams will reflect spontaneously only when the outcome interdependence is high, i.e. when the team members perceive that achievement of goals by their fellow team members is beneficial for meeting their own goals. If the team members feel that achievement of the goals of their fellow team members is detrimental to achievement of their own goals, i.e. when outcome interdependence is low, then team members may detest the time and efforts spent in reflection and group decision-making.

The proposition was tested with team members of actual software development projects and found valid. The moderating effect of outcome interdependence on the effect of team reflexivity on its effectiveness was observed as predicted. Further, as predicted, software development projects adopting agile methods, showed higher outcome interdependence, team reflexivity and thereby higher team effectiveness. However, the higher team effectiveness, defined as a comparison of intended versus actual project outcomes (Hoegl and Gemuenden 2001), was at the expense of its efficiency, defined as a comparison of intended versus actual project inputs such as time (schedule) and costs (budget) expended to accomplish the project outcomes (Hoegl and Parboteeah 2006). This intriguing phenomenon is discussed and its implications for practice and future research elaborated.

\section{Literature Review}

"Work design describes how jobs, tasks, and roles are structured, enacted, and modified, as well as the impact of these structures, enactments, and modifications on individual, group, and organizational outcomes" (Grant and Parker 2009). Since the industrial revolution, work design theories have been useful in describing and explaining the behaviors of employees (Hackman and Oldham 1974). Work design is known to affect employee task, psychological and health outcomes such as performance, turnover and absenteeism, job satisfaction, team cohesiveness, internal work motivation, stress, and burnout (e.g., Parker and Wall 1998). We investigate the evolution in work design theories to understand the origins of the concepts of reflexivity and outcome interdependence in teams and how and under what conditions they might impact work performance.

Work design concepts originated with the concepts of division of labor and specialization (Babbage 1835; Smith 1776). Specialization and division of labor creates interdependencies within work groups or departments (Saavedra et al. 1993; Thompson 1967; van de Ven et al. 1976). The concepts of Charles Babbage and Adam Smith influenced the methods of software development during the early stages of its evolution. Methods such as the waterfall method (Royce 1970) and its variants encouraged division of labor leading to specialized roles of business analysts, system architects, programmers and testers (Melnik and Maurer 2006). These plan-driven methods were also influenced by the concepts of Taylor (1911) who introduced Scientific Management with the aim of controlling every work activity, from the simplest to the most complicated.

However, repetitive jobs were found to be boring, tiring, dissatisfying and potentially damaging to mental health (Fraser 1947; Walker and Guest 1952). These costs of division of labor and task specialization diverted the focus of researchers to human issues at work. Further, increasing uncertainty at the work place implies that managers and industrial engineers defining and assigning jobs to the employees may not work. When uncertainty is low, the one best way of dealing with them is known as events are predictable. In contrast, where there is high uncertainty, the occurrence of problems is less predictable, and so are the means of solving them. "Uncertainty indicates inability to anticipate when problems will arise and/or lack of knowledge about how best to deal with them" (Jackson 1989). Thus greater autonomy should be provided to teams for organizing work to be able to adjust to quickly changing environment.

Responding to these concerns, Socio-Technical Systems (STS) design was introduced as the first alternative work design paradigm to challenge the scientific management principles of Taylor. STS perspective of work design proposes self-organizing autonomous groups of people to accomplish work (Trist 1981). The aforementioned transition in focus from process to people was also seen in the evolution of software development methods with the introduction of the Agile manifesto in 2001. Agile development proponents questioned the assumption that change and uncertainty can be controlled through a high degree of advanced planning and rigid processes (Nerur et al. 2005).

Software developers realized that while the Tayloristic plan-driven methods do work well in stable conditions, under uncertain conditions managers planning, assigning and controlling tasks of software developers may not work 
(Melnik and Maurer 2006). Agile methods therefore emphasize reflexivity among team members in organizing and performing work. Multi-skilled team members may perform several roles of programmers, testers, designers and requirements analysis with flexibility based on work demands. The focus on developing working products rather than paper artifacts and components of plan-drive methods enhances task identity and task significance through integration. Agile projects emphasize face-to-face communication over documentation. They continuously track and reflect on project progress and change through daily stand up meetings, sprint reviews and project retrospectives.

However self-management and organization too has its own costs. It requires group members to invest time in acquiring knowledge about the product and the process as a whole and develop larger analytical and problem-solving capability. Group members should be able to deal with disruptive events as and when they arise. Also, it takes considerable effort to establish and maintain cooperative culture (Johnson and Johnson 2005). There are costs associated with social connectedness of cooperation and the emotional and task burden of individuals are high. Unless mitigated, self-interest of group members might predominate and lead group members to influence group decision making towards narrow interests by withholding of information, and make attempts to divert resources away from team goals (Zand 1981). We suggest that by offering collective goals and rewards or outcome interdependence, a practice not alien to self-managing teams, an environment for spontaneous reflexivity can be created. We therefore hypothesize in the next section the relationships between team reflexivity, outcome interdependence and team performance. The goal is to theoretically and empirically investigate the direct impacts and interplay between cooperative outcome interdependence and reflexivity in enhancing team performance.

\section{Theory Development}

There are two types of process control systems: defined and empirical. According to the industrial process control theory "defined" processes are repeatable, i.e. they always accomplish the specified outcome for a given a set of inputs after a certain set of controls are applied (Schwaber 1997). These processes are well defined and understood and are referred to as white box systems. On the other hand "empirical" processes are referred to as black-box systems. These processes are complex and have unpredictable outcomes for a given set of inputs. Software development is considered as a black box system (Schwaber 1997). Also, software cannot be fully specified up-front (Hislop et al. 2002) as business requirements and technologies change rapidly during the course of software development project. Further "the true requirements emerge over time because what the users initially thought they wanted gets refined as software develops" (Kakar 2014).

Not all teams facing such ambiguity and change may find it easy to define problems and prioritize their resolution. However, teams that are reflexive are more adept at exploring new ways of looking at situations and examine hidden patterns in an uncertain environment and as a result more likely to find superior and timely solutions to their problems (Hirokawa 1990; Schwenk 1988). Self-reflection enables teams to constantly scan and assess dynamic situations and come to a clear and accurate understanding of complex environmental and technological changes. Further it fosters better communication and exchange of ideas among team members and enhances their ability to handle challenging tasks. Constant reflection is also likely to boost the role-breadth self-efficacy of individual team members i.e. "confidence in their capabilities to carry out a wider range of tasks and responsibilities effectively" (Parker 1998). Reflexive teams through their constant interactions are more aware of the expertise of the team members and can thereby identify the right person/s to effectively address emerging problems. This effective use of team knowledge and expertise can lead to higher team performance (Hoegl and Parboteeah 2006). Thus,

Hypothesis 1 Team reflexivity is positively related to team performance

Outcome interdependence is defined as "the extent to which team members believe that their personal benefits and costs depend on successful goal attainment by other team members" (van der Vegt et al. 1998). Outcome interdependence is achieved through the way the goals are defined and achieved and the way the performance is rewarded (Wageman 1995; Johnson and Johnson 1989). For example super-ordinate or group goals may be set at different levels of task interdependencies and autonomy such as for programmers working independently as well as those engaged in paired programming.

When the outcome interdependence is low employees will shun interdependence and favor autonomy. By contrast, high outcome interdependence can act as the social glue within the group irrespective of the levels of task interdependence and autonomy. Common goals and rewards will mitigate the deleterious impacts of simultaneously having high task interdependence and autonomy by increasing cooperation and work motivation. Employees will view superior performance of fellow employees as enablers and not as a threat and look forward to collaborating with them to achieve group goals. Team members working under such circumstances of positive are more open-minded regarding others' arguments and desires, 
more concerned about each others' outcomes, and more inclined to search for solutions and compromises (Campbell and Pritchard 1976; Deutsch 1949, 1973, 1980; Guzzo 1986; Johnson and Johnson 1989; Johnson et al. 1981; Tjosvold et al. 1991; Tjosvold and Deemer 1980) thereby enhancing team performance. This leads us to the following hypothesis:

Hypothesis 2 Outcome interdependence will enhance team performance

If the team members feel that achievement of the goals of their fellow team members are not related to their own goals or at cross purpose with them (low outcome interdependence) then they are likely to consider time spent in reflection with other team members a waste of time or even detrimental to their self-interest. They will be interested in focusing on accomplishing their own task for personal rewards and may withhold information that they perceive might benefit the group at their expense. Further, lack of clarity on group goals may also hamper team performance. By contrast, common goals and rewards (high outcome interdependence) help pull team members together and encourage team members to pursue their own tasks and cooperate with other team members in addressing challenges facing the group as a whole. Employees will be more likely to share information and will look forward to collaborating with other team members in participative reflection and problem solving to achieve group goals in light of changing environment. This leads us to the following hypothesis:

Hypothesis 3 Outcome interdependence will moderate the impact of reflexivity on team performance such that when the outcome interdependence is high the impact of reflexivity on team performance will be positive and when the outcome interdependence is low the impact of reflexivity on team performance will be negative

According to a typology of interdependence (Fig. 1) by Tesluk et al. (1997) the degree of interdependence increases from pooled to sequential to reciprocal to intensive. Pooled interdependence does not involve any interaction between team members. Performance of the group is an aggregation of individual team member's performance. In sequential interdependence, work flows unidirectionally from one member to another. Reciprocal interdependence is similar to sequential except that the workflow is bidirectional. In intensive interdependence the entire group must interact with each other to accomplish group goals.

Plan driven methods of software development such as the waterfall method and its variants promote conformance to plan and encourage division of labor leading to specialized roles of business analysts, system architects, programmers and testers (Melnik and Maurer 2006). In plan-
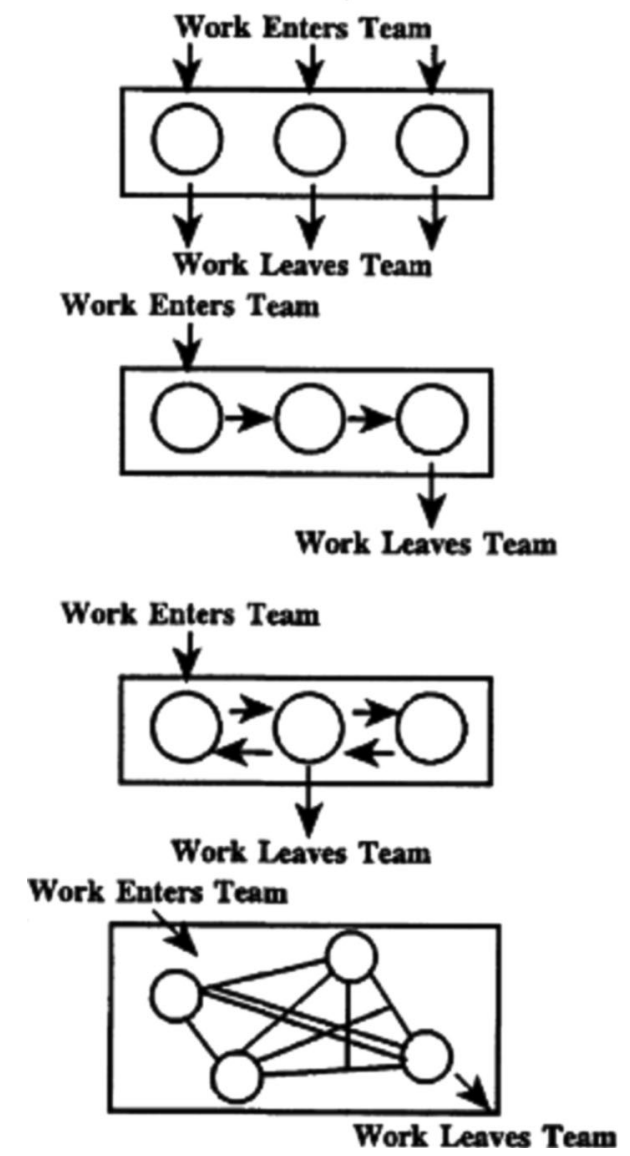

Fig. 1 Typology of interdependence (adapted from Tesluk et al. 1997)

driven methods tasks are process-driven, team members have little autonomy. Sequential interdependence predominates as can be seen from Fig. 2 for waterfall model (Royce 1987). Sequential development phases entail fewer points of employee interfaces. Typically, testers interact with coders but not with designers, designers interact with requirement gatherers but not with system implementers. In an uncertain environment this approach is not likely to result in successful outcomes.

By contrast the agile methods deploy self-managing teams. Teams and its members have more autonomy. Outcome interdependence is high. Group goals and collective responsibility are the norm (Beck 1999; Scrum Alliance 2008) and points of employee interface are many (Fig. 3). Practices such as pair programming, planning game and daily stand-up meeting (Beck 1999; Scrum Alliance 2008) continually promote reflection among team members and an ability to respond quickly and effectively to change. This leads us to the following hypothesis and the conceptual model (Fig. 4):

Hypothesis 4 Software projects adopting plan-driven methods will be lower in reflexivity and outcome 
Fig. 2 Sequential interdependence of plan driven methods (Royce 1987)

Fig. 3 Intensive interdependence of agile methods (Beck 1999)
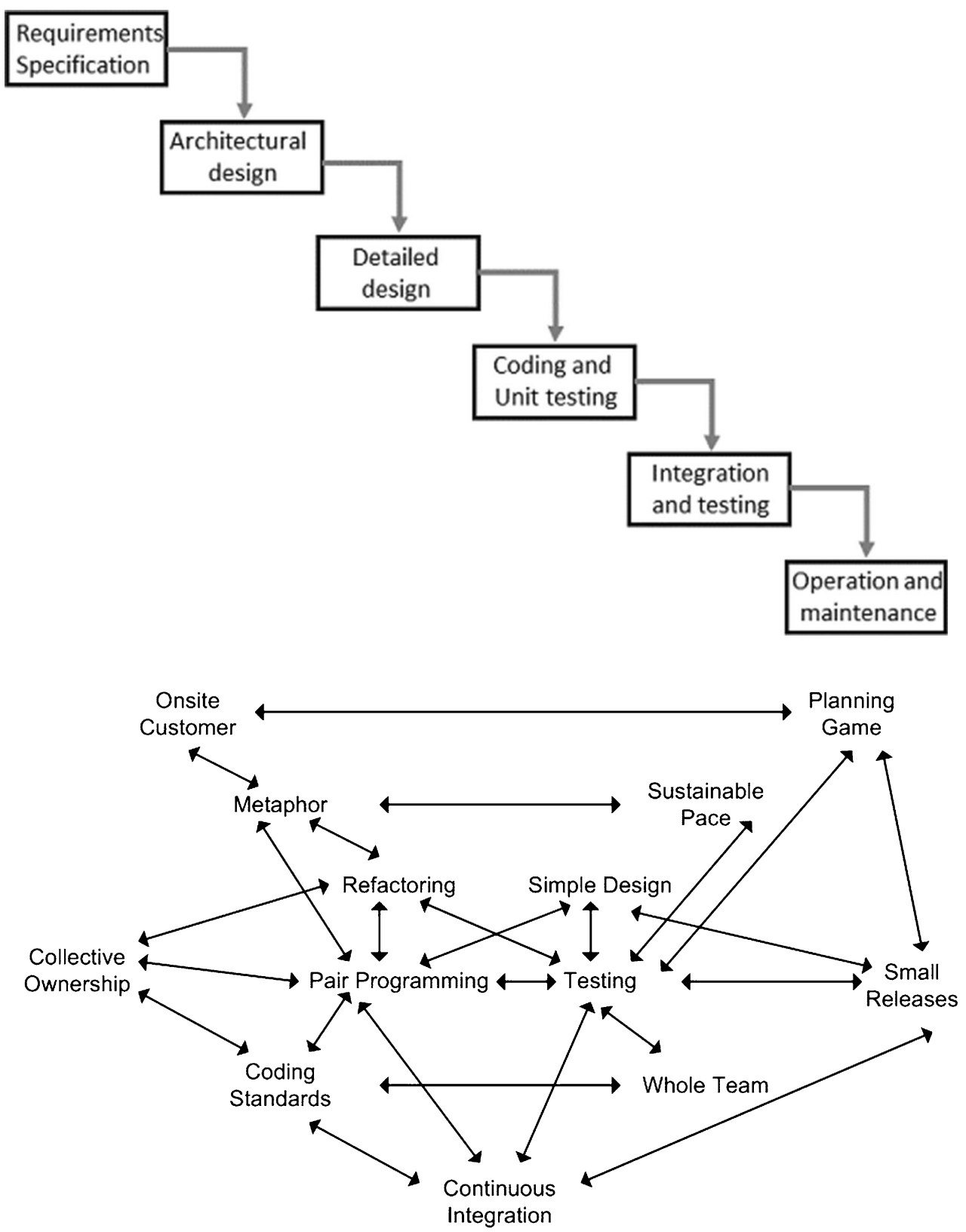

interdependence than software projects adopting agile methods and will therefore demonstrate lower team performance

\section{Research Methodology}

\subsection{Study Setting and Design}

To test the proposed hypotheses we conducted a multi-year survey with development team members of 34 software projects. The developers were employees of the university's industry partners and graduate students of the university who had to complete a real-life software project with the industry partners which included 18 companies with 3 of them in the Fortune 500 list. The graduate students were all academically accomplished and were admitted to the graduate degree program by invitation only. The type of projects included 14 which the industry partners characterized as Waterfall method, $4 \mathrm{~V}$-method, 9 Extreme programming, 3 Scrum, 1 Crystal methodologies, 1 Dynamic Software development method (DSDM), 1 Feature Driven Development (FDD) and 1 Lean Software Development Method (LSDM) (Appendix C provides a brief description of each method).

The university has a policy of randomly assigning the students to alphabetically listed projects in the ascending order of their last names. The capstone projects enable 


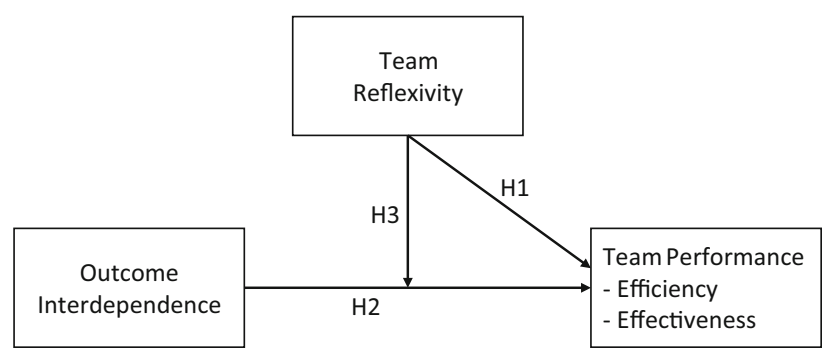

Fig. 4 Conceptual model

students to work on a real-life project and provide them with job opportunities. The university has a high placement rate and many of the students who work on the capstone projects are employed by the industry partners. The study was completed over a 4-year period involving 332 developers who answered a pen and pencil questionnaire based survey at the end of completion of their projects. The students worked on the project along with the development team of the industry partners in their premises as well as at the university.

Of the 34 projects 18 were new software development projects and 16 were upgrades or customization of existing software. The role of the students was determined by the industry partners that included requirements analysis, designing, writing of code and testing depending on the project requirements. The projects lasted for a period between 4 and 6 months. The researchers and their associates in collaboration with the industry partners collected data on project completion. The subjects were between 21 and 39 year old, 194 males and 148 females who worked on software development projects involving between 6 and 16 team members. The average age of the subjects was 28.4 years, average experience on real life software development projects was 6.3 years and the average number of team members working on the projects was 8.4.

\subsection{Variables Used in the Study}

The independent variables are team reflexivity and outcome interdependence. The dependent variable is team performance of software development projects. Tested measures from prior literature were adapted to capture data pertaining to these variables.

Reflexivity A five item scale developed by Hoegl and Parboteeah (2006) was used for measuring reflexivity. A sample item from this scale is: "my team adjusted its task performance strategies in response to changes in the context and progress of the project."

Outcome Interdependence A bipolar scale of six items (van der Vegt et al. 1998) to measure outcome interdependence was used. A sample item from this scale is:
"When my colleagues succeed in their jobs, it works out negatively/positively for me."

Team Performance Team performance was measured using the scale developed by Hoegl and Gemuenden (2001). The team performance scale consists of two subscales one for team effectiveness and another for team efficiency. Effectiveness sub-scale reflects a comparison of actual versus intended outcomes, whereas efficiency subscale reflects a comparison of actual versus intended inputs. A sample item from team effectiveness subscale is "All demands of the customers have been satisfied". A sample item from the team efficiency subscale is "The project was completed within schedule".

For a complete list of items please see Appendix A. These measures used a 9-point Likert scale with anchors of 1 (strongly disagree) and 9 (strongly agree) for reflexivity and team performance and bipolar adjectives at opposite ends of the 9 point scale for outcome interdependence. A 9 point scale was chosen because expanding the number of choice-points beyond 5- or 7-points increases scale sensitivity without damaging scale reliability (Cummins and Gullone 2000). The value for each measure was created by averaging the value of the scale items. Responses were coded such that high values represented high levels of the items of the measures. Some items were reverse coded.

\subsection{Procedure}

Subjects answered a paper-and pencil based survey that captured demographic data that included age, gender and years of experience in software development projects and data on independent variables, team reflexivity and outcome interdependence (Appendix A). The data collected represented the response from $84 \%$ of developers who participated in the 34 development projects. The questionnaire items listed were scrambled. Data on the dependent variable, reflexivity, was collected from the sponsor of the project three months later.

\subsection{Method of Analyses}

To establish reliability and validity of the measures used in the study factor analysis was performed and internal reliabilities and the correlation matrix of the measures were examined. Moderated Hierarchical Multiple Regression (MHMR), a widely recommended method for testing moderating relationships or interactions between independent variables (Cohen 1978; Dunlap and Kemery 1987; Stone and Hollenbeck 1989; Cortina 1993), was used for analyzing the data, MHMR analysis reveals how well each independent variable predicts the dependent variable, after extracting variance due to other independent and control variables in the regression equation and interaction effects 
after extracting variance due to independent and control variables. It tests for the significance of the increment in criterion variance explained by the main effects after accounting for the variance due to control variables and then increment in criterion variance explained by interaction terms beyond those attributed to the main effects.

Team size was controlled for in the analysis. Large team sizes make it more difficult for team members to interact with all other team members given the dramatic increase of possible individual links between team members as team size grows (Steiner 1966). It can thus affect both collaborative task process and team performance (Hackman 1987; Campion et al. 1993). As team size was not the variable of interest in this study, in our hypotheses testing, MHMR analysis was conducted to test the direct effects and interaction between team reflexivity and outcome interdependence on team performance after controlling for team size.

\section{Results and Analyses}

The factor analysis procedure was done using IBM $^{\odot}$ SPSS $^{\odot}$ Statistics Version 19. Dimension reduction was performed on the data pertaining to the 4 measurement scales. The results of Varimax rotation showed that the four factors extracted represented each of the four scales. All items of a scale (Team Performance: T1 to T10 for team effectiveness and T11 to T15 for team efficiency, Outcome Interdependence: $\mathrm{O} 1$ to O6, and Reflexivity: R1 to R5) loaded on the respective factors (highlighted in bold in Appendix B). Convergent and discriminant validity between scales were evident (Appendix B) by the high loadings within factors $(>0.50)$ and no cross loadings $(>0.40)$ between factors. The internal reliabilities of the scales used in the study - task interdependence, outcome interdependence, autonomy and reflexivity - were then examined and found to be greater than 0.70 (Table 1).

Table 2 provides the means and standard deviations of the data collected in this survey. From the correlation between variables in Table 4 it is clear that none of the correlations are too high $(>0.65)$ demonstrating that each scale is adding something new.

Table 1 Internal reliability of scales

\begin{tabular}{llc}
\hline Name of the scale & Cronbach's Alpha & No. of items \\
\hline Outcome interdependence (OI) & 0.818 & 6 \\
Reflexivity (R) & 0.866 & 5 \\
Team effectiveness (TE1) & 0.855 & 10 \\
Team efficiency (TE2) & 0.889 & 5 \\
\hline
\end{tabular}

Table 2 Means, standard deviations, correlations

\begin{tabular}{lllllll}
\hline Variable & Mean & Std. dev & 1 & 2 & 3 & 4 \\
\hline OI & 5.234 & 0.905 & 1 & & & \\
R & 5.625 & 0.922 & 0.111 & 1 & & \\
TE1 & 5.711 & 0.930 & $0.142 *$ & $0.287 * *$ & 1 & \\
TE2 & 5.823 & 0.816 & -0.056 & -0.043 & 0.023 & 1 \\
\hline
\end{tabular}

$* \mathrm{p}<0.05 * * \mathrm{p}<0.01 * * * \mathrm{p}<0.001$

Table 3 Moderated hierarchical multiple regression analysis results for team effectiveness

\begin{tabular}{|c|c|c|c|}
\hline Step & Variables added in each step & $\begin{array}{l}\text { Change in } \\
\text { R-square }\end{array}$ & $\begin{array}{l}\text { Regression } \\
\text { coefficients }\end{array}$ \\
\hline \multirow[t]{2}{*}{1} & Control variables & & \\
\hline & $\begin{array}{l}\text { Age, gender, experience and } \\
\text { size of development projects }\end{array}$ & $0.076 * *$ & $\begin{array}{l}0.023,0.041 \\
0.641 * \\
-3.171 * *\end{array}$ \\
\hline \multirow[t]{3}{*}{2} & Main effect & & \\
\hline & Reflexivity (R) & $0.092 * * *$ & $5.263 * * *$ \\
\hline & $\begin{array}{l}\text { Outcome interdependence } \\
\text { (OI) }\end{array}$ & $0.079 * *$ & $2.640 * *$ \\
\hline \multirow[t]{2}{*}{3} & Interaction effect & & \\
\hline & $\mathrm{R} \times \mathrm{OI}$ & $0.021 * *$ & $2.277 * *$ \\
\hline
\end{tabular}

$* \mathrm{p}<0.05 * * \mathrm{p}<0.01 * * * \mathrm{p}<0.001$

Before analyzing the results of MHMR in Table 3, the normal probability plot was examined to ascertain normal distribution of residuals. The Variance Inflation Factor (VIF) option was included in the analyses to explore the extent of multicollinearity in the results. All the VIF values were less than 1.5 indicating a lack of multicollinearity in results (Hair et al. 2006).

Results from MHMR analysis in Table 3 show that both outcome interdependence and reflexivity have a positive effect on team effectiveness. Further a significant $(p<0.01)$ interaction among outcome interdependence and reflexivity in predicting team effectiveness was observed. Analyses of the interaction using the slope test (Aiken and West 1991) reveals that at high outcome interdependence (1 Standard Deviation above mean) reflexivity has a significantly $(\mathrm{p}<0.01)$ positive impact $(B=0.324)$ on team effectiveness while at low outcome interdependence (1 Standard deviation below mean) reflexivity has a significantly $(\mathrm{p}<0.01)$ negative impact $(\mathrm{B}=-0.129)$ on team effectiveness.

Results from MHMR analysis in Table 4 show that both outcome interdependence and reflexivity have a non-significant effect on team efficiency. Thus Hypotheses 1 and 2 were not fully supported as the efficiency component of performance was not supported. Further a significant $(\mathrm{p}<0.01)$ interaction among outcome interdependence and reflexivity in predicting team efficiency was observed. 
Table 4 Moderated hierarchical multiple regression analysis results for team efficiency

\begin{tabular}{|c|c|c|c|}
\hline Step & Variables added in each step & $\begin{array}{l}\text { Change in } \\
\text { R-square }\end{array}$ & $\begin{array}{l}\text { Regression } \\
\text { coefficients }\end{array}$ \\
\hline \multirow[t]{2}{*}{1} & Control variables & & \\
\hline & $\begin{array}{l}\text { Age, gender, experience and } \\
\text { size of development projects }\end{array}$ & 0.034 & $\begin{array}{l}0.029,0.056 \\
0.824 * \\
-1.134 * *\end{array}$ \\
\hline \multirow[t]{3}{*}{2} & Main effect & & \\
\hline & Reflexivity (R) & 0.002 & 0.026 \\
\hline & $\begin{array}{l}\text { Outcome interdependence } \\
\text { (OI) }\end{array}$ & 0.001 & 0.013 \\
\hline \multirow[t]{2}{*}{3} & Interaction effect & & \\
\hline & $\mathrm{R} \times \mathrm{OI}$ & 0.011 & $-1.396 * *$ \\
\hline
\end{tabular}

$* \mathrm{p}<0.05 * * \mathrm{p}<0.01 * * * \mathrm{p}<0.001$

However, analyses of the interaction using the slope test (Aiken and West 1991) reveals that at low outcome interdependence (1 Standard Deviation below mean) reflexivity has a non-significant impact $(\mathrm{B}=0.036)$ on team effectiveness while at high outcome interdependence (1 Standard deviation above mean) reflexivity has a significantly $(\mathrm{p}<0.01)$ negative impact $(\mathrm{B}=-0.157)$ on team efficiency. Thus results from Tables 3 and 4 show that Hypotheses 1-3 were partially supported. Although all the predicted main and interaction effects of outcome interdependence and reflexivity were supported for team effectiveness, they were not supported for team efficiency.

The results in Table 5 partially support Hypothesis 4 . Although as predicted outcome interdependence, team reflexivity and task effectiveness were significantly higher $(\mathrm{P}<0.01)$ for software development projects using Agile methods compared with those using plan-driven methods, team efficiency was found to be significantly $(\mathrm{p}<0.01)$ higher in plan-driven projects compared to agile projects.

\section{Discussion}

The results of the study show that Hypothesis 1 and 4 were all partially supported and highlight the complex relationships among the variables of the proposed conceptual model (Fig. 4). The results of the study show that while high outcome interdependence and high team reflexivity have salutary effect on team effectiveness, low outcome interdependence and low team reflexivity are favorable for team efficiency. These results are intriguing and create a Catch-22 situation for organizations interested in improving performance of software development teams. We had expected that the interaction impact of high reflexivity and high outcome interdependence would be synergistic for both efficiency and effectiveness and the interaction impact of low reflexivity and low outcome interdependence would be antagonistic for both efficiency and effectiveness (Hypothesis 3 ). Do these findings imply that efficiency can be engendered only at the expense of effectiveness and vice versa?

Past research has noted that individuals and teams rarely reflect spontaneously. Teams tend to behave in habitual ways, even when faced with evidence that this behavior might be dysfunctional in reaching team or organizational goals (Gersick and Hackman 1990). In addition, teams often place more emphasis on action leaving no time for learning and reflection on past behavior. Outcome interdependence creates the condition for fruitful reflexivity. Teams are better able to reflect if the group goals are clear (Locke and Latham 1990). Establishing common ground is essential for collaboration (Flor 1998). Additionally, group rewards reduces dysfunctional conflicts. Breakdown in coordination is a significant contributor to bugs and design flaws (Petre 2004). As effectiveness is related to the "output" of work one can expect the observed synergistic effects of reflexivity and outcome interdependence on team effectiveness.

The opposite of reflexivity is relying on habitual routines. Group members are known to be more comfortable with routines (Gersick and Hackman 1990). Familiar well-practiced routines lead to savings in time and energy required for reflection leading to better efficiency. But without exploring the alternatives this approach may not always lead to the best decision, i.e. this approach may compromise effectiveness. This explains why the process focused plan driven methods demonstrated greater efficiency and lower effectiveness in the study while self-

Table 5 Comparison of results for agile and plan-driven methods

\begin{tabular}{|c|c|c|c|c|c|c|c|}
\hline \multirow[t]{2}{*}{ Variables measure } & \multicolumn{3}{|c|}{ Agile methods } & \multicolumn{3}{|c|}{ Plan-driven methods } & \multirow[t]{2}{*}{ Difference in means } \\
\hline & Mean & Standard deviation & $\mathrm{N}$ & Mean & Standard deviation & $\mathrm{N}$ & \\
\hline Outcome interdependence (OI) & 5.602 & 0.851 & 163 & 4.887 & 1.065 & 169 & $0.715 * *$ \\
\hline Reflexivity (R) & 6.105 & 0.942 & 163 & 5.172 & 1.124 & 169 & $0.903 * * *$ \\
\hline Team effectiveness (TE1) & 6.4879 & 0.947 & 163 & 4.980 & 0.974 & 169 & $1.507 * *$ \\
\hline Team efficiency (TE2) & 4.976 & 0.811 & 163 & 6.620 & 0.834 & 189 & $-1.644 * *$ \\
\hline
\end{tabular}

$* \mathrm{p}<0.05 * * \mathrm{p}<0.01 * * * \mathrm{p}<0.001$ 
Table 6 Moderated hierarchical multiple regression analysis results for team effectiveness of new software development projects

\begin{tabular}{|c|c|c|c|}
\hline Step & Variables added in each step & $\begin{array}{l}\text { Change in } \\
\text { R-square }\end{array}$ & $\begin{array}{l}\text { Regression } \\
\text { coefficients }\end{array}$ \\
\hline \multirow[t]{2}{*}{1} & Control Variables & & \\
\hline & $\begin{array}{l}\text { Age, gender, experience and } \\
\text { size of development projects }\end{array}$ & $0.086^{* *}$ & $\begin{array}{l}0.018,0.071 \\
0.711 * \\
-2.951 * *\end{array}$ \\
\hline \multirow[t]{3}{*}{2} & Main effect & & \\
\hline & Reflexivity (R) & $0.103 * * *$ & $4.879 * * *$ \\
\hline & $\begin{array}{l}\text { Outcome interdependence } \\
\text { (OI) }\end{array}$ & $0.099 * *$ & $2.967 * *$ \\
\hline \multirow[t]{2}{*}{3} & Interaction effect & & \\
\hline & $\mathrm{R} \times \mathrm{OI}$ & $0.028 * *$ & $2.458 * *$ \\
\hline
\end{tabular}

$* \mathrm{p}<0.05 * * \mathrm{p}<0.01 * * * \mathrm{p}<0.001$

organizing reflexive agile teams demonstrated higher effectiveness but lower efficiency.

However, the aforementioned discussion brings up another interesting question. Tasks are known to differ widely. In line with the aforementioned discussion, should habitual routines (lower reflexivity) not demonstrate both higher efficiency as well as higher effectiveness for welldefined tasks where coping with change is minimal? Also, should higher reflexivity not demonstrate both higher effectiveness and efficiency for more innovative tasks? In innovative projects the teams face continual uncertainty and ambiguity (Sicotte and Langley 2000). Team reflexivity is likely to be very helpful in such equivocal situations when there is confusion and ambiguity about what needs to be done and lack of knowledge about the consequences of actions and future events. Reutilized routines in such cases will not help in achieving either efficiency or effectiveness goals. Similarly, for well defined tasks reflexivity is a sheer waste of time and efforts and outcome interdependence is not likely to help either. Efficient well-defined processes and clearly defined roles (division of labor) are more likely to result in higher efficiency as well as effectiveness.
To investigate if this is so, we conduct four supplementary MHMR analyses, two for upgrade and customization projects and another two for new software development projects. Upgrade and customization projects are relatively well defined in terms of inputs (existing software) and expected outputs. By contrast, new software development projects starts from a more ambiguous position. The requirements for the new software are not so well-defined initially and evolve over time (LoureiroKoechlin 2008). It may involve using unfamiliar technology, interacting with new potential users and facing unforeseen problems during its development. Therefore, will we observe the synergistic effects of high reflexivity and high outcome interdependence on overall team performance in the case of new software development and antagonistic effects of high reflexivity and outcome interdependence in the case of software upgrade projects?

From Tables 6 and 7 we see that reflexivity and outcome interdependence have significant $(\mathrm{p}<0.01)$ and positive impact on both team efficiency and effectiveness for new software development projects. Further, a significant $(p<0.01)$ interaction among outcome interdependence and reflexivity in predicting team efficiency and effectiveness was observed. Analyses of the interaction using the slope test (Aiken and West 1991) reveals that at high outcome interdependence (1 Standard Deviation above mean) reflexivity has a significantly $(\mathrm{p}<0.01)$ positive impact $(\mathrm{B}=0.324,0.253$ ) on team effectiveness and efficiency respectively while at low outcome interdependence (1 Standard deviation below mean) reflexivity has a significantly $(\mathrm{p}<0.01)$ negative impact $(\mathrm{B}=-0.129$, -0.89 ) on team effectiveness and efficiency respectively.

From Tables 8 and 9 we see that reflexivity and outcome interdependence have non-significant impact on both team efficiency and effectiveness for upgrade projects. Further, a significant $(\mathrm{p}<0.01)$ interaction among outcome interdependence and reflexivity in predicting team efficiency and effectiveness was observed. Analyses of the interaction using the slope test (Aiken and West 1991) reveals that

Table 7 Moderated hierarchical multiple regression analysis results for team efficiency of new software development projects

\begin{tabular}{llll}
\hline Step & Variables added in each step & Change in R-square & Regression coefficients \\
\hline 1 & Control variables & & $0.019,0.047,0.729^{*},-1.135^{*}$ \\
& Age, gender, experience and size of development projects & $0.034^{*}$ & $0.107^{* *}$ \\
& Main effect & & $0.142^{* *}$ \\
& Reflexivity (R) & $0.083^{*}$ & $0.051^{*}$ \\
& Outcome interdependence (OI) & & $1.460^{* *}$ \\
\hline
\end{tabular}

$* \mathrm{p}<0.05 * * \mathrm{p}<0.01 * * * \mathrm{p}<0.001$ 
Table 8 Moderated hierarchical multiple regression analysis results for team effectiveness for software upgrades

\begin{tabular}{llll}
\hline Step & Variables added in each step & $\begin{array}{l}\text { Change in } \\
\text { R-square }\end{array}$ & $\begin{array}{l}\text { Regression } \\
\text { coefficients }\end{array}$ \\
\hline $1 \quad$ Control variables & & \\
& Age, gender, experience and & $0.065^{* *}$ & $0.045,0.021$, \\
& size of development projects & & $0.699^{*}$, \\
& & & $-2.056^{* *}$ \\
$2 \quad$ Main effect & & \\
$\quad$ Reflexivity (R) & 0.002 & 0.026 \\
$\quad$ Outcome interdependence & 0.004 & 0.044 \\
$\quad$ (OI) & & \\
$\quad$ Interaction effect & & \\
$\quad \mathrm{R} \times$ OI & $0.031^{*}$ & $-2.393^{* *}$ \\
\hline
\end{tabular}

$* \mathrm{p}<0.05 * * \mathrm{p}<0.01 * * * \mathrm{p}<0.001$

high outcome interdependence and reflexivity (1 Standard Deviation below mean) has a significantly $(\mathrm{p}<0.01)$ negative impact $(\mathrm{B}=-0.278,-0.182)$ on team effectiveness and efficiency respectively while low outcome interdependence and reflexivity (1 Standard deviation below mean) has a significantly $(\mathrm{p}<0.05)$ positive impact (B $=0.067,0.072)$ on team effectiveness and efficiency respectively.

The main findings of the study presented in the results and analyses and discussion sections are summarized in Table 10.

\section{Contributions and Limitations}

This study, a first of its kind, models and tests the relationship between outcome interdependence, reflexivity and team performance. By expounding the complex relationships between these constructs the study provides a systematic way of enhancing performance of software development teams. The findings of the study suggests that for innovative software development projects high levels of reflexivity and outcome interdependence are best for team performance while for routine (non-innovative) software
Table 10 Summary of findings

1 The study findings reveal the complex relationships between team reflexivity, outcome interdependence and team performance by proposing and testing the direct (main) and indirect (interactional) effects of team reflexivity and outcome interdependence on team performance

2 Both team reflexivity and outcome interdependence have a positive direct effect on team effectiveness but a negative direct effect on team efficiency

3 Team reflexivity and outcome interdependence have a synergistic interactional impact on team effectiveness but an antagonistic interactional effect on team efficiency

4 Agile teams demonstrated higher reflexivity, higher outcome interdependence and higher effectiveness compared to plan driven methods

5 Plan driven teams demonstrated lower reflexivity, lower outcome interdependence and higher efficiency compared to agile teams

6 For routine software development projects, teams with low reflexivity and low outcome interdependence perform better in efficiency as well as effectiveness than teams high in reflexivity and high in outcome interdependence

7 By inference from points 5 and 6 above plan driven teams will perform better than agile teams for routine software development projects

8 For innovative software development projects, teams with high reflexivity and high outcome interdependence will perform better in efficiency as well as effectiveness than teams low in reflexivity and low in outcome interdependence

9 By inference from points 4 and 8 above agile teams will perform better than plan driven teams for innovative software development projects

development projects low levels of reflexivity and outcome interdependence are best.

The findings have practical implications. Levels of both reflexivity and outcome interdependence can be controlled through team design, leadership styles (transformational versus transactional), setting collective (versus individual) goals and providing group (versus individual) rewards. Hirst et al. (2004) found that facilitative leader behaviors can positively engender team reflexivity. Team members can be trained to improve on their social skills such as the ability to interact with other people, non-evaluatively and actively

Table 9 Moderated hierarchical multiple regression analysis results for team efficiency for software upgrades

\begin{tabular}{|c|c|c|c|}
\hline Step & Variables added in each step & Change in R-square & Regression coefficients \\
\hline \multirow[t]{2}{*}{1} & Control variables & & \\
\hline & Age, gender, experience and size of development projects & 0.034 & $0.045,0.039,0.687^{*},-1.13^{*}$ \\
\hline \multirow[t]{3}{*}{2} & Main effect & & \\
\hline & Reflexivity (R) & 0.002 & 0.026 \\
\hline & Outcome interdependence (OI) & 0.001 & 0.013 \\
\hline \multirow[t]{2}{*}{3} & Interaction effect & & \\
\hline & $\mathrm{R} \times \mathrm{OI}$ & 0.011 & $-1.53 * *$ \\
\hline
\end{tabular}

$* \mathrm{p}<0.05 * * \mathrm{p}<0.01 * * * \mathrm{p}<0.001$ 
listening to others, communicating with them clearly and effectively and developing the ability to understand and respect other people's opinions (Faix and Laier 1996; Brodbeck 1994; Stevens and Campion 1994). Development of analytical skills to perform and improve jobs can empower group members to engage in reflection. Further, practices such as frequent face to face interactions in the form of daily stand-up meetings and team planning exercises highlight outcome interdependence and enhance reflexivity.

These practices are well known in agile methods of software development (Beck 1999; Scrum Alliance 2008). Hence we expect agile methods to perform better for innovative projects. However, low reflexivity and outcome interdependence can be expected in plan-driven methods of software development. Focus on role specialization, promotion of habitual behaviors through defined processes, and emphasis on skill based training plan-driven methods minimize reflexivity and outcome interdependence. Hence we can expect plan-driven methods to perform better for routine software development tasks such as upgrades and customization. These insights are in our view a unique contribution of this study and should be further explored in future research. "Theoretically comprehending the distinction between agile methods and plan-driven methods is a concern begging for research attention" (Dingsøyr et al. 2012). This study is one step forward in that direction.

These insights are supported by past research which suggests that while mechanistic structures influence exploitative behavior and attainment of goals related to process, stability and efficiency, organic structures promote explorative behavior and attainment of goals related to flexibility, adaptability and innovation (Burns and Stalker 1961; Duncan 1976; O'Reilly and Tushman 2004; Tushman and O'Reilly 1996; He and Wong 2004; Jansen et al. 2005). Agile methods represent the organic structures as they focus on adaptation rather than prediction and control of the mechanistic plan-driven methods (Vinekar et al. 2006). Traditional plan driven methods facilitate exploitation of existing knowledge through codification of the process of software development while agile methods facilitate exploration through exchange of tacit knowledge (Boehm 2002). Thus plan-driven development is desirable when requirements are stable and predictable while agile development is suitable under conditions of uncertainty (Boehm and Turner 2004).

However, the contributions of the study should be viewed in light of the following limitations. Although software development methods are broadly classified into two categories, the Agile methods and the Plan-driven or Taylorist methods, within each category there are many different methods each with their own principles and practices making comparisons between them confusing. For example, there are many Agile methods currently in use such as Extreme programming, Scrum, Crystal methodologies, Dynamic Software development method (DSDM), Feature Driven Development (FDD) and Lean Software Development Method (LSDM) with each focusing heavily on some of the principles of the agile manifesto and completely ignoring others making it impossible to reach any conclusions on specific agile methods and their use (Conboy and Fitzgerald 2004). Hence the results only broadly reflect the distinction between Agile methods and plan-driven methods. The sample size did not permit further statistical analyses of differences within these two major paradigms. Future studies may test the validity of the results obtained in the study for specific methods of software development within these two broad categories.

Yet, it may be noted that agile and plan-driven methods represent "ideal types". Ideal types help in theorizing and promote deeper understanding of a phenomenon (Jessop 2002). But software development methods are never found in pure form. Many variants of the pure forms exist. Mixes and remixes of practices (Dingsøyr et al. 2012) promoted by these two major paradigms are found in work situations depending on context such as organizational culture, volatility of user requirements, skill profile of the development team and complexity of the software developed. Yet, the findings of the study do provide useful insights into the characteristic differences between the two major paradigms of software development.

Further, the trade-offs made during research design might have impacted the generalizability and validity of the results both positively and negatively. Choosing a student sample may have limited the applicability of the results to teams of experienced software developers. Yet this design choice mitigated the effects of individual differences among subjects on the validity of the findings. The subject choice provided a fairly high response rate from a large relatively homogeneous sample unencumbered by previous work experiences, preferences and biases. A sample of experienced developers might have varied greatly in age, educational backgrounds, length of experience, specialized skills and roles such as programmers, testers or designers and biases due to past work experience such as preference for a particular software development methodology. Additionally, the university setting allowed access to software development projects with multiple industry partners providing an opportunity for greater generalizability of the results. Findings from, for example, multiple projects within a single organization might have been considered idiosyncratic.

\section{References}

Aiken L, West S (1991) Multiple regression: testing and interpreting interactions. Sage, Thousand Oaks 
Babbage C (1835) On the economy of machinery and manufacturing. Knight, London

Beck K (1999) Extreme programming explained: embrace change, 1st edn. Addison-Wesley Professional, Boston

Boehm B (2002) Get ready for agile methods, with care. Comput 35(1):64-69

Boehm B, Turner R (2004) Balancing agility and discipline: evaluating and integrating agile and plan-driven methods. In: Proceedings 26th international conference on software engineering (ICSE 2004), pp 718-719

Brodbeck FC (1994) Intensive Kommunikation lohnt sich für SEProjekte. In: Brodbeck FC, Frese M (eds) Produktivität und Qualität in Software-Projekten. Oldenbourg, München, pp 51-67

Burns T, Stalker GM (1961) The management of innovation. Tavistock, London

Campbell JP, Pritchard RD (1976) Motivation theory in industrial and organizational psychology. In: Dunnette MD (ed) Handbook of industrial and organizational psychology. Rand McNally, Chicago

Campion MA, Medsker GJ, Higgs AC (1993) Relations between work group characteristics and effectiveness: implications for designing effective work groups. Pers Psychol 46:823-850

Capretz L (2003) Personality types in software engineering. Int J Hum Comput Stud 58(2):207-214

Cohen J (1978) Partialled products are interactions: partialled powers are curve components. Psychol Bull 85:858-866

Conboy K, Fitzgerald B (2004) Toward a conceptual framework of agile methods: a study of agility in different disciplines. In: Proceedings of XP/Agile Universe, Springer

Cortina JM (1993) Interaction, nonlinearity, and multicollinearity: implications for multiple regression. J Manag 19(4):915-922

Cummins RA, Gullone E (2000) The case for subjective quality of life measurement. In: Proceedings of the second international conference on quality of life in cities, pp 74-93

De Dreu C (2002) Team innovation and team effectiveness: the importance of minority dissent and reflexivity. Europ J Work Organ Psychol 3:285-298

Deutsch M (1949) An experimental study of the effects of cooperation and competition upon group process. Hum Relat 2:199-231

Deutsch M (1973) The resolution of conflict: constructive and destructive processes. Yale University Press, New Haven

Deutsch M (1980) Fifty years of conflict. In: Festinger L (ed) Retrospections on social psychology. Oxford University Press, New York, pp 46-77

Dingsøyr T, Nerur S, Balijepally V, Moe NB (2012) A decade of agile methodologies: towards explaining agile software development. J Syst Softw 85(6):1213-1221

Duncan RB (1976) The ambidextrous organization: designing dual structures for innovation. In: Kilmann RH, Pondy LR, Slevin D (eds) The management of organization. North-Holland, New York, pp 167-188

Dunlap WP, Kemery ER (1987) Failure to detect moderating effects: is multicollinearity the problem? Psychol Bull 102:418-420

Faix WG, Laier A (1996) Soziale Kompetenz: Wettbewerbsfaktor der Zukunft, 2nd edn. Gabler, Wiesbaden

Flor N (1998) Side-by-side collaboration: a case study. Int J Hum Comput Stud 49:201-222

Fraser R (1947) The incidence of neurosis among factory workers. Report No. 90, Industrial Health Research Board, HMSO, London

Gersick CJ, Hackman JR (1990) Habitual routines in task-performing groups. Organ Behav Hum Decis Process 47:65-97

Grant AM, Parker SK (2009) Redesigning work design theories: the rise of relational and proactive perspectives. Acad Manag Ann 3(1):317-375
Guzzo RA (1986) Group decision making and group effectiveness in organizations. In: Goodman P (ed) Designing effective work groups. Jossey-Bass, San Francisco

Hackman JR (1987) The design of work teams. In: Lorsch JW (ed) Handbook of organizational behavior. Prentice-Hall, Englewood Cliffs, pp 67-102

Hackman JR, Oldham GR (1974) The job diagnostic survey: an instrument for the diagnosis of jobs and the evaluation of job redesign projects. http://files.eric.ed.gov/fulltext/ED099580.pdf. Accessed 1 May 2017

Hair JF Jr, Black WC, Babin BJ, Anderson RE, Tatham RL (2006) Multivariate data analysis, 6th edn. Prentice Hall, New Jersey

He Z, Wong P (2004) Exploration vs. exploitation: an empirical test of the ambidexterity hypothesis. Organ Sci 15(4):481-494

Hirokawa RY (1990) The role of communication in group decisionmaking efficacy: a task-contigency perspective. Small Group Res 21:190-204

Hirst G, Mann L, Bain P, Pirola-Merlo A, Richter A (2004) Learning to lead: the development and testing of a model of leadership learning. Leadersh Q 15:311-327

Hislop GW, Lutz MJ, Naveda JF, McCracken WM, Mead NR, Williams LA (2002) Integrating agile practices into software engineering courses. Comput Sci Educ 12(39):169-185

Hoegl M, Gemuenden H (2001) Teamwork quality and the success of innovative projects: a theoretical concept and empirical evidence. Organ Sci 12(4):435-449

Hoegl M, Parboteeah KP (2006) Team reflexivity in innovative projects. R\&D Manag 36(2):113-125

Jackson SE (1989) Does job control control job stress? In: Sauter SL, Hurrell JJ Jr, Cooper CL (eds) Job control and worker health. Wiley, Chichester

Jansen JJ, Van Den Bosch FA, Volberda HW (2005) Managing potential and realized absorptive capacity: how do organizational antecedents matter? Acad Manag J 48(6):999-1015

Jessop B (2002) Liberalism, neoliberalism, and urban governance. Antelope 34:105-125

Johnson DW, Johnson RT (1989) Cooperation and competition: theory and research. Edina, MN Interaction Book

Johnson DW, Johnson RT (2005) New developments in social interdependence theory. Genet Soc Gen Psychol Monogr 134(4):285-358

Johnson DW, Maruyama G, Nelson D, Skon S (1981) Effects of cooperative, competitive, and individualistic goal structures on achievement: a meta-analysis. Psychol Bull 89:47-62

Kakar AK (2014) Teaching theories underlying agile methods in a systems development course. In: 47th Hawaii International Conference on System Sciences (HICSS), pp 4970-4978

Locke EA, Latham GP (1990) A theory of goal-setting and task performance. Prentice Hall, Englewood Cliffs

Loureiro-Koechlin C (2008) A theoretical framework for a structuration model of social issues in software development in information systems. Syst Res Behav Sci 25(1):99-109

Melnik G, Maurer F (2006) Comparative analysis of job satisfaction in agile and non-agile software development teams. In: International conference on extreme programming and agile processes in software engineering. Springer, Berlin, Heidelberg, pp 32-42

Nerur S, Mahapatra R, Mangalaraj G (2005) Challenges of migrating to agile methodologies. Commun ACM 48(5):72-78

O'Reilly CA III, Tushman ML (2004) The ambidextrous organization. Harv Bus Rev 82(4):74-81

Osterman P (2000) Work reorganization in an era of restructuring: trends in diffusion and effects on employee welfare. Ind Labor Relat Rev 53:179-196

Parker SK (1998) Role breadth self-efficacy: relationship with work enrichment and other organizational practices. J Appl Psychol $83: 835-852$ 
Parker SK, Wall T (1998) Job and work design: organizing work to promote well-being and effectiveness. Sage, London

Parker SK, Wall TD, Cordery J (2001) Future work design research and practice: towards an elaborated model of work design. J Occup Organ Psychol 74:413-440

Petre M (2004) Team coordination through externalised mental imagery. Int J Hum Comput Stud 61(2):205-218

Royce WW (1970) Managing the development of large software systems. In: Proceedings of IEEE WESTCON, p 8

Royce WW (1987) Managing the development of large software systems: concepts and techniques. In: ICSE, pp 328-339

Saavedra R, Earley PC, Van Dyne L (1993) Complex interdependence in task-performing groups. J Appl Psychol 78:61-72

Schwaber K (1997) Scrum development process. In: Business object design and implementation. Springer, London, pp 117-134

Schwenk CR (1988) The essence of strategic decision making. Lexington, DC Heath

Scrum Alliance (2008) World Wide Web electronic publication. www.scrumalliance.org/view/scrum_framework. Accessed 8 July 2015

Sicotte H, Langley A (2000) Integration mechanisms and R\&D project performance. J Eng Technol Manag 17:1-37

Smith A (1776) An inquiry into the nature and causes of the wealth of nations. Strahan and Cadell, London

Steiner ID (1966) Models for inferring relationships between group size and potential group productivity. Behav Sci 11:273-283

Stevens MJ, Campion MA (1994) The knowledge, skill, and ability requirements for teamwork: implications for human resource management. J Manag 20(2):503-530

Stone EF, Hollenbeck JR (1989) Clarifying some controversial issues surrounding statistical procedures for detecting moderator variables: empirical evidence and related matters. J Appl Psychol 74:3-10

Taylor FW (1911) The principles of scientific management. Harper, New York

Tesluk PE, Mathieu JE, Zaccaro SJ, Marks MA (1997) Task and aggregation issues in the analysis and assessment of team performance. In: Brannick MT, Salas E, Prince C (eds) Team performance and measurement: theory, methods, and applications. Erlbaum, Mahwah, pp 197-224
Thompson JD (1967) Organizations in action. McGraw-Hill, New York

Tjosvold D, Deemer DK (1980) Effects of controversy within a cooperative or competitive context on organizational decision making. J Appl Psychol 65:590-595

Tjosvold D, Andrews IR, Struthers JT (1991) Power and interdependence in work groups. Group Organ Stud 16:285-299

Trist E (1981) The evolution of socio-technical systems. Occasional paper

Tushman ML, O'Reilly CA III (1996) Ambidextrous organizations: managing evolutionary and revolutionary change. Calif Manag Rev 38(4):8-30

Van De Ven AH, Delbecq AL, Koenig RJ (1976) Determinants of coordination modes within organizations. Am Soc Rev 41(2):322-338

Van der Vegt GS, Emans BJM, Van de Vliert E (1998) Motivating effects of task and outcome interdependence in work teams. Group Organ Manag 23:12-144

Vinekar V, Slinkman CW, Nerur S (2006) Can agile and traditional systems development approaches coexist? An ambidextrous view. Inf Syst Manag 23(3):31-42

Wageman R (1995) Interdependence and group effectiveness. Adm Sci Q 40:145-180

Walker CR, Guest RH (1952) The man on the assembly line. Harv Univ Press, Cambridge

Wall TD, Cordery JL, Clegg CW (2002) Empowerment, performance, and operational uncertainty: a theoretical integration. Appl Psychol 51:146-169

West MA (1996) Reflexivity and work group effectiveness: a conceptual integration. In: West MA (ed) Handbook of work group psychology. Wiley, Chichester, pp 555-579

West MA (2000) Reflexivity, revolution and innovation in work teams. In: Beyerlein MM, Johnson DA, Beyerlein ST (eds) Product development teams, vol 5. JAI, Stamford, pp 1-29

Wright BM, Cordery JL (1999) Production uncertainty as a contextual moderator of employee reactions to job design. J Appl Psychol $84: 456-463$

Zand DE (1981) Information, organization, and power: effective management in the knowledge society. McGraw-Hill, New York 